\title{
Dynamics of Risk Degree of Innovation-Driven Growth at Higher Education Institutions
}

\author{
Irina E. Nadutkina, Viktor M. Zaharov, Maksim V. Selyukov", Svetlana A. Kompaniec, \\ Natalya P. Shalygina, Mariya V. Lugovskaya \\ Belgorod State University, Russia
}

Received July 22, 2019; Revised September 21, 2019; Accepted September 30, 2019

Copyright $(2019$ by authors, all rights reserved. Authors agree that this article remains permanently open access under the terms of the Creative Commons Attribution License 4.0 International License

\begin{abstract}
In this article, the analysis of dynamics of risk degree of innovation-driven growth at higher education institutions is discussed. The survey has been employed in this paper and the data analyzed by SPSS software. Results revealed that the resulting risks are regularly encountered in a modern Russian higher educational institution: inability to provide necessary financial support for educational activities; inability to provide required modern material and technical basis; challenges and failures in collaboration with enterprises for organizing practical training for students and the absence of practical training programs at the university. It is also indicated that the risk event might lead to different results: negative, positive, or null (if everything went according to the plan).
\end{abstract}

Keywords Innovational Activities, Risk Theory, Education Institution, Technological, Social Distances

\section{Introduction}

The sphere of higher education institutions in Russia is of particular research interest in new circumstances when observed as a specialist training system, from the perspective of possessing a risk management component. Primarily, the management risks are correlated with the activities at the university in the context of the quality of education, which is a highly distinctive field, which is characterized by its particular risks that are distinct from which ordinarily mentioned in the theory of risk management.

According to the specialists' research, the introduction of brand-new management decisions in organization and economy, and also the implementation of fundamental engineering in science and technology at higher education institutions of the country increase the degree of risk of innovation-driven growth immensely.

It is noteworthy that human activity is considerably diverse, but each type possesses the following common attributes to a different extent: ambivalence, random nature, and probability value. These features are an integral component of the concept of risk. The consequences of risk may be different, and its varieties are different. There are specific risks typical for particular types of human activities along with the risks, which are common traits for all fields of activity.

Organizations are subject to certain risks when carrying out innovational developments. The degree of risk is ambiguous by various innovational measures. Less risky are such events, which imply partial modernization of equipment and production technology, the update of production output, cost reduction, and material interest of employees in the outcome of their labor. These provided risks are mandatory circumstances for a consistent increase in organizational effectiveness.

The prevailing trend of development of world civilization regarding globalization and transparency of social systems is the factor for the creation and development of social risks. Consequently, modern society seems like a complexly organized system with social processes that support constant developments.

Different sorts of social risks create an object of investigation of many scientific disciplines: in social studies, cultural anthropology, political studies, economy studies, etc. The impact of the transformation processes on the production and reproduction of social risks is investigated in sociology, where the focus is placed on the activity of the individual, social groups, value priorities, and behavioral models. In this instance, when the selection of action is the choice of many alternatives, a significant feature of social reality is formed by the social risks, in a way that the uncertainty of the future is extremely high. Therefore, any activity of a social subject is risky; the authors agree that risk-free behavior does not exist. 
Russia's background explicates that a systematic approach to the solution of this problem implies the development of innovative activities in scientific, technological, and educational fields of higher education. Innovational activities of higher education institution solve the problem of commercialization of knowledge and technology developed by the research staff and lecturers and include strong interaction among employees, lecturers, and market by employing the infrastructure of the higher education institution.

Innovative activities of higher education institutions possess certain peculiarities that are representative of the educational sphere. In particular, it must be considered that the concept of the university complex was first officially introduced just in the Russian Government's Decree of 17.09.2001 № 676 "On the University Complexes" and this fact provided the unity of education and innovation processes. This issue implies that innovation activities in higher education receive the status of significant varieties of activity in conjunction with education (learning) and science. Simultaneously, innovation-based activity is always objective and centered on a particular area. For the system of professional higher education, such fields are correlated to the scientific and educational sphere.

Consequently, the innovational activities in the field of science and education should be presented as a mandatory and profiled element for the whole system in the system of the Ministry of Education and Science of the Russian Federation, as a necessary condition of translational motion and sustainable development; they should be understood and accepted by academic staff and personnel. At the moment, commercialization of the results of scientific and educational activity becomes a prerequisite for survival, and a factor of the constant development of higher education institutions, even one of the principal instruments improve its competitiveness on the market of educational services and products, labor market and high technology and services market. The most remarkable circumstance for the development of innovation management in high school is the identification and fixation of new scientific outcomes and entered market segments (Babintsev, 2007: 287; Fauskanger, \& Bjuland, 2018; Ebrahim Abadi, \& Namdar, 2016).

The personality, school, society, employers, and state are encountering different challenges and come into risky conditions while achieving its objectives. In the risk theory, «a risk» is defined as a possibility of losses related to the specificity of certain natural phenomena and human activities; the probability of introducing incorrect management decisions or rejection of necessary management decisions; the probability of obtaining unplanned outcomes by engaging one or more activity. A risk event may lead to different results: negative, positive, or null (if everything went according to the plan). Concerning the present case, the risk would fail to approach the objectives that have been set by interested individuals depending on the quality of education. For instance, a company will not be able to improve the effectivity of work immediately due to the absence of staff's qualification.

Furthermore, the participants can obtain results beyond their expectations because of applying effective quality management system in institutions of higher education as well as the application of the system of predicting future demands of education service for consumers and graduates. For example, a student (a person) can get more valuable knowledge while studying at a university compared to the time before the admission to the higher educational institute. It can be concluded that risk in the field of higher education institutions should be classified as a speculative risk (since it is still probable to get a positive outcome in achieving the planned objects by a dominant-negative or null result).

The problem of innovation development management of professional higher education institutions (HEI) is mainly a problem of the consciousness of participants included in the process. Social barriers of innovations are group interests that come into contrary with the definition of innovation; they are the interests of the employees, department groups of professionals whom the decision of problems of implementation of the innovational high school management depends on. Regardless of the tightness of the existing situation, there are always social groups interested in sustaining the status quo because of having accustomed to it. The mentioned groups are inclined to confront undesirable alterations directly or indirectly (Becker 2015: 147). Resistance to innovations possesses both objective and subjective reasons. Extensively, it is occasionally caused by unpreparedness and low ability of management of universities to influence public opinion, by underestimation of information support in innovational activity of universities in particular fields, incapacity to motivate the participants of social process, to apply technologies which assist in engaging the most promising staff from the perspective of their creativity (Bourdieu, 2016: 242; Sailaukyzy, et al 2018).

\section{Literature Review}

The research of A.L. Kulikov is devoted to the impact of the growth of the intellectual component of human resources on the sustainability of the organization's development, the problems of its accumulation and its employment (Gaponenko, A.D. Kosmin, S.M. Klimova, O.N. Melnikov, and others). The socio-cultural aspects of the activities of a modern university are reconsidered in the studies of G. Behmann, A. Grudzinsky, P. Drucker, V. Inozemtsev, M. Castells, etc. Recently, much consideration has been made to comprehending the idea of university in a modern socio-cultural context. Substantive features of the place and role of the university in society are included in 
the publications of R. Barnett, Z. Bauman, M. Gusakovsky, J. Derrida, V. Kurenno, G. Petrova, B. Ridings, E. Strogetskaya, AR Tuzikova, J. Habermas, and others.

\section{Model, Data and Methodology}

There is no agreement among researchers regarding the conceptual strategy for risk management of innovative development at the university; its meaning is the central question, in which solution of the strategy of innovative development at the university depends on the critical extent.

In this respect, the importance of the sociological analysis of the risk management of innovative development increases, particularly. It can be remarked that the subsequent risks are regularly confronted in a modern Russian higher educational institution while analyzing the current circumstances: inability to provide necessary financial support for educational activities; inability to provide required modern material and technical basis; challenges and failures in interaction with enterprises for organizing practical training for students and the absence of practical training programs at the university. The problems, as mentioned above, are causing risks of having an inadequate number of highly qualified and skilled lecturers due to their movement to higher-paid positions. Insufficient funding leads to failure in providing students with modern literature, and access to information resources, failure to formulate favorable circumstances for active scientific, practical, social, cultural, and sports activity. Another peculiarity should be noted connected with the risk at higher education institutions - the low initial level of graduates. It is supposed that the research interest in this issue should be promoted and supported by the scientific community as a risk of innovative development at higher education institutions. The higher education institution also encounters the problem of unbalance between used training aids and modern requirements; such problems can be avoided if the administration of a higher education institution actively supports the idea to build-up a same level of the innovation culture at the university.

In this investigation, a survey of the Degree of Risk of Innovation was carried out among all staff of higher education institutions whose validity and Cronbach's alpha approved reliability. The survey was employed to identify the innovation risk factors in the institutions, and its purpose was to determine what factors and barriers of innovation risk exist in educational organizations. The results of this survey are significant in the way that the barriers of innovation in educational organizations can only be investigated at the informal interface, and the best method to obtain this information is conducting a survey.

\section{Empirical Results}

Modern higher professional education institutions of the country, which are struggling for rating and defending their status positions, should organize a severe attempt to develop the proper level of innovational culture, where demand for innovation should result by itself in most circumstances. It should be implied by the innovative development at the higher educational institution surveyed as a separate organization, that a university as a consumer introduces necessary developments on its own to satisfy their requirements while improving at educational, scientific and technical levels.

The field of higher education in Russia, regarded as a system of training specialists from the perspective of the presence of managerial risk is of particular research interest in new conditions. Initially, management risks are associated with the activities of the university in the circumstances of the quality of education, which is a rather specific area, which is defined by its particular risks, distinct from those traditionally regarded in the theory of risk management. Furthermore, the problem of managing the innovative development of institutions of higher professional education mainly depends on the way of risk prediction and development risk management to be well conducted in a turbulent university environment. Consequently, throughout the survey, the majority of respondents show that the innovative development of the university is associated with significant risks, as indicated in the following table.

Table 1. Result of Survey to Assess the Development Risk

\begin{tabular}{|c|c|c|}
\hline \multirow{2}{*}{$\begin{array}{c}\text { Do you agree with the statement that the } \\
\text { innovative development of a university is } \\
\text { associated with significant risks? }\end{array}$} & \multicolumn{2}{|c|}{ Amount } \\
\cline { 2 - 3 } & Abs. & $\%$ \\
\hline Yes & 27 & $48.21 \%$ \\
\hline No & 13 & $23.21 \%$ \\
\hline No data & 11 & $19.64 \%$ \\
\hline Hard to answer & 5 & $8.93 \%$ \\
\hline Total & 56 & $100.00 \%$ \\
\hline
\end{tabular}

The most reliable reasons are the risks associated with innovative development based on the respondents, addressed in table 2 .

Table 2. The Most Reliable Reasons

\begin{tabular}{|l|c|c|}
\hline Mark the most typical causes of the risks of & \multicolumn{2}{|c|}{ Amount } \\
\cline { 2 - 3 } $\begin{array}{l}\text { innovative development of the university in } \\
\text { your opinion }\end{array}$ & Abs. & $\%$ \\
\hline $\begin{array}{l}\text { excessive bureaucratization of activity } \\
\text { insufficient qualification of scientific and } \\
\text { pedagogical personnel }\end{array}$ & 17 & $30.36 \%$ \\
\hline $\begin{array}{l}\text { lack of qualifications of university } \\
\text { management staff }\end{array}$ & 11 & $19.64 \%$ \\
\hline $\begin{array}{l}\text { insufficient level of practical experience in the } \\
\text { management of the university administration }\end{array}$ & 9 & $16.07 \%$ \\
\hline no data & 3 & $5.36 \%$ \\
\hline high turnover rate & 2 & $3.57 \%$ \\
\hline Total & 56 & $100.00 \%$ \\
\hline
\end{tabular}


Indeed, many risks are as results of reforming processes of institutions of higher professional education, since they firstly imply an alteration in the principles of the universities, with the purpose of restructuring, which in turn is connected to new forms of work organization, cost reduction, improved financial and economic results of activities of universities. Secondly, the reform is correlated to measures of state support for these developments, which in turn implies the requirement to organize management activities on a project basis, to which collectives are not always ready.

Regarding the risks at the university, it is necessary to understand what measures can be practiced to enhance the risk management of the innovative development of universities.

Table 3. The Survey of Improvement of Risk Management

\begin{tabular}{|l|c|c|}
\hline \multirow{2}{*}{$\begin{array}{l}\text { What do you think should be performed to } \\
\text { enhance the risk management of the innovative } \\
\text { development of the university? }\end{array}$} & \multicolumn{2}{|c|}{ Amount } \\
\cline { 2 - 3 } & Abs. & $\%$ \\
\hline $\begin{array}{l}\text { improve the skills of university management } \\
\text { staff in risk management }\end{array}$ & 31 & $55.36 \%$ \\
\hline $\begin{array}{l}\text { balance the amount of funding of educational } \\
\text { and research activities }\end{array}$ & 29 & $51.79 \%$ \\
\hline $\begin{array}{l}\text { improve the level of information and analytical } \\
\text { work of university management staff }\end{array}$ & 16 & $28.57 \%$ \\
\hline $\begin{array}{l}\text { create the } \\
\text { development of corporate culture }\end{array}$ & 15 & $26.79 \%$ \\
\hline $\begin{array}{l}\text { form a new particular structure related to the } \\
\text { risk management of innovative development of } \\
\text { the university }\end{array}$ & 13 & $23.21 \%$ \\
\hline raise the level of organizational communication & 13 & $23.21 \%$ \\
\hline $\begin{array}{l}\text { strengthen the responsibility of university } \\
\text { management staff for management decisions }\end{array}$ & 12 & $21.43 \%$ \\
\hline no date & 3 & $5.36 \%$ \\
\hline to reduce the wage gap & 1 & $1.79 \%$ \\
\hline hard to answer & 56 & $100.00 \%$ \\
\hline Total & & - \\
\hline
\end{tabular}

In the practice of innovational processes management, mainly if related to risky circumstances, it is necessary to pay specific attention to the promotion of innovations. In this connection, an essential factor plays a role in increasing the ability of stimuli to affect the behavior of participants of the innovational process throughout the process of implementation of the organizational development strategy.

\section{REFERENCES}

[1] Rothaermel, F. T., \& Hess, A. M. (2007). Building dynamic capabilities: Innovation driven by individual-, firm-, and network-level effects. Organization science, 18(6), 898-921.Babintsev, V. P. (2007). Management of Innovation

[2] Johnston, L., Hamilton, E., \& Zhang, J. (2008). Learning through engaging with higher education institutions: a small business perspective.Dyatchenko, L. Y. (1993). Social Technologies in the Management of Social Processes. M., Belgorod, 1, 225-228. (In Russian).

[3] Ebrahim Abadi, M., \& Namdar, Sh. (2016). Comparison between the legal nature of commercial factoring and similar legal institutions. UCT Journal of Social Sciences and Humanities Research, 4(2), 10-15.

[4] Fauskanger, J., \& Bjuland, R. (2018). Deep Learning as Constructed in Mathematics Teachers' Written Discourses. International Electronic Journal of Mathematics Education, 13(3), 149-160. https://doi.org/10.12973/iejme/2705

[5] Nadutkna, I. E. (2010). Strategy of Information Support of Innovation Processes in the Region. Scientific Journal of BSU. Series "Philosophy. Sociology. Law", 2(73), 77-84.

[6] Selyukov, M., Zaharov, V., Gulyaev, I., Shalygina, N., Nalbantov, A., \& Lisnichaya, M. (2018). Development of labor resources as a factor of sustainable economic growth in the conditions of sanctions. J. Fundam. Appl. Sci., 10, 1274-1283.

[7] Soja, E. (2010). Seeking Spatial Justice. Minnesota: University of Minnesota Press, pp: 256.

[8] Sailaukyzy, A., Shakuova, R., Sak, K., \& Lebedeva, T. (2018). Contemporary view to the history of Kazakhstan's democratic journalism and publicism. Opción, 34(85-2), 774-799.

[9] Thompson, C. J. (2007). Countervailing market responses to corporate co-optation and the ideological recruitment of consumption communities. Journal of Consumer Research, 34(2), 135-152.

[10] Tkhorikov, B. A. (2008). Development of Technology for Image Management in a Medical Establishment. Scientific Bulletin of BSU. "Philosophy Sociology Law", 4, 216-220. (In Russian).

[11] Zombart, V. (2003). Sociologiya. Per. s nem. I. D Markusona. M.: URSS, pp: 138. (In Russian). 